\title{
Identification and Traceability of Spiritous Drinks based on UV-spectrometry and Conductometry
}

\author{
Yury Belkin
}

\begin{abstract}
This article is devoted to the identification and detection of adulterated alcoholic beverages on the example of brandy and vodka. According to different opinions, up to $40 \%$ of spiritous beverages turn out to be adulterated or counterfeit. Most commonly used to identify such adulteration analytical methods are either too expensive or time-demanding. The other important thing that there is no standard method developed for objective tracing of spirits to the level of a production lot. The paper proposes an express method for detecting adulterated alcoholic beverages based on the use of two analytical methods of different nature: conductometry and UV-spectrometry. The possibility of these methods' joint use for identification of alcoholic beverages with the standard or by common features (non-signature identification) is proved by the usage of statistical methods on data got from analytical measurements and sensory evaluation of 171 drinks' samples. The samples represent different countries of product origin, brands, ageing periods. Firstly we found out informative wavelength bands, spectral curve forms and conductivity limits for different types of drinks, both genuine and adulterated -adulteration was previously revealed by sensory test. Then, using k-means cluster analysis we developed typical spectra for 2 'styles' of genuine brandies and adulterated brandies, for vodkas the same work was done using simpler statistical techniques (means and variation analysis). Finally, an algorithm for spiritous beverages identification and tracing is given. Additionally, changes in the values of the electrical conductivity and UV spectra during shelf life that do not affect the suitability of the proposed method were studied.
\end{abstract}

Keywords : spiritous beverages, brandy, vodka, $U V$-spectroscopy, conductometry, identification, adulteration.

\section{INTRODUCTION}

$S_{\text {pirituous beverages (spirits) are a category of alcoholic }}$ beverages produced using neutral (rectificated) alcohol or distillates. This category includes drinks as spirits of vinicultural origin (brandy, cognac, armagnac et al.), spirits of fruit origin (schnapps, slivovice et al.), whisky, rum, tequila, other traditional spirits and alcoholic beverages produced using neutral alcohol (vodka, liqueur and others). Quality assessment of spirits is an important problem in food science and analytical chemistry, because, according to different

Manuscript received on December 27, 2020.

Revised Manuscript received on December 31, 2020.

Manuscript published on February 28, 2021.

* Correspondence Author

Yury Belkin*, Commodity Science and Expertise Department, Plekhanov Russian University of Economics, Moscow, Russia. Email: Belkin.YD@rea.ru

(C) The Authors. Published by Blue Eyes Intelligence Engineering and Sciences Publication (BEIESP). This is an open access article under the CC BY-NC-ND license (http://creativecommons.org/licenses/by-nc-nd/4.0/) sources, from $20 \%$ to $50 \%$ of sold spirits are either of bad quality or adulterated. Adulteration of spirits is very profitable and hard to be identified as such drinks consist of more than 700 individual chemical substances [1], which are permanently interacting with each other and changing their chemical forms. A great number of analytical methods have been developed for spirits' quality control and authenticity determination; these methods are of different origin (chromatographic, spectroscopic, electrochemical, wet chemistry). The most often used method is gas chromatography (GC) with mass spectrum or flame ionization detection, sample preparation by solid phase microextraction is widely used [2], [3]. High performance liquid chromatography (HPLC) and capillary electrophoresis can be used to identify non-volatile compounds in spirits [4], [5], including analyzing the ionic composition of the spirit. Another approach is to not analyze separate components of spirits, but use some integral parameters to identify adulteration. This includes spectroscopy methods (color identification, IR, UV spectrum analysis), antioxidant activity analysis methods, electronic sensory systems [6]-[10]. Nevertheless today there is no unified approach to spirits' adulteration identification and authenticity determination, none of the methods mentioned above can be used alone for such purposes, a complex of methods is always needed. Another problem is that most of the used methods are expensive and demand much time for one analysis. The purpose of this research was to develop a complex of cheap and fast instrumental methods that will be able to assess quality and authenticity of spirits by the example of spirits of vinicultural origin and vodkas. The hypothesis was that usage of two analytical methods of different origin: conductometry and UV-spectrometry would help to identify spiritous drinks and their main properties with a good probability.

\section{EXPERIMENTAL DETAILS}

\section{A. Materials}

124 samples of brandy and 47 samples of vodka were taken as the objects for this research. This includes samples produced mostly in Russia, Armenia, France and Spain, brandies with the ageing period from 0,5 to 15 years.

\section{B. Sensory test}

All the samples were tasted according to the standard procedure accepted in Russia - color, transparency, smell and taste were assessed in order to

\section{Published By:}

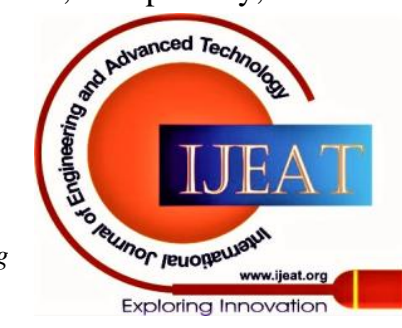




\section{Identification and Traceability of Spiritous Drinks based on UV-spectrometry and Conductometry}

find whether each sample complies to Russian standards on brandy and vodka or not [11]-[12]. The expert panel consisted of 6 experts having experience in sensory analysis of alcoholic drinks. $31,45 \%$ of brandy samples and $12,77 \%$ of vodka samples turned out to be adulterated.

These results helped to classify the samples into two groups: adulterated and authentic ones. In the further experiment and data analysis we try to find the parameters of conductivity and UV-spectrum that prove samples to be adulterated or authentic.

\section{Conductometry test}

Conductometry was measured in native samples without any sample preparations. Conductometers with automatic thermocompensation "Anion 4150" (Russia) and "ECTester 138(II)" (China) were used. The relative error was no more than $2 \%$. In order to study the possibility of implementing the method regardless of the conductometer model used and reduce the cost of implementation, the results of measuring electrical conductivity with two conductometers were compared on 6 samples of brandy, as well as on 6 samples of vodka. Previously, both the conductivity meter was calibrated using the same standard solutions of the type "Hanna Instruments HI 7030". According to the results of the comparison, the difference between the values obtained on different hardware is no more than $8.00 \%$ for brandies and no more than $7.4 \%$ for vodkas. Taking into account the error of the sample observation (the sample was considered to be actually random small, confidence probability $\mathrm{p}=0.95$ ), the maximum relative deviation was no more than $8.9 \%$ for brandies and no more than $7.8 \%$ for vodkas

\section{UV-spectrometry test}

UV-spectra of absorbance were registered on Shimadzu UV-2450 (Japan) in quartz cells with $\mathrm{d}=1 \mathrm{~cm}$ for vodkas and $\mathrm{d}=0.1 \mathrm{~mm}$ for brandies. The wavelength band was set from 200 to $400 \mathrm{~nm}$, the absolute error turned out to be not more than 0,005 AU. According to the spectra variability analysis it was found out that the informative wavelength bands on which spectra vary to a much extent are: from 220 to $350 \mathrm{~nm}$ for brandies and from 200 to $230 \mathrm{~nm}$ for vodkas. In further calculations only these informative wavelength bands were taken into consideration.

\section{E. Data processing}

Data analysis was processed using Microsoft Excel and STATISTICA 10. To reduce the volume of data stored in the prospect information and analytical system, UV absorption spectra were presented in an approximate form. Based on the criteria of maximum reliability and minimizing the number of the theoretical curve coefficients, the approximation of the UV absorption spectra curves was made by a superposition of a third-degree polynomial and six Gauss curves $\left(\mathrm{R}^{2}\right.$ not less than 0.99999). Fityk software utility was used to discover the optimal approximation [13]. In this paper, in all cases of testing scientific hypotheses on a set of samples, the calculated error of the sample observation was considered. Unless otherwise specified, all samples were considered non-repetitive and random small, and the probability was assumed to be $p=0.95$. The sum of squared residuals (SSR) was used as a criterion describing the proximity of two spectral curves. The linearity of the spectral curves and the relationship of quantitative features to each other were evaluated using the Pearson linear correlation coefficient (R). To assess the relationship between qualitative variables and quantitative variables, the nonparametric correlation coefficient $\gamma$ was used. Also the k-means method was used for cluster analysis of samples.

\section{RESULT AND DISCUSSION}

\section{A. Typical values of conductivity and optical absorbance for brandies and vodkas}

During the analysis typical limits of conductivity for brandies and vodkas considering both adulterated and not adulterated samples were found (see table I).

Table- I: Typical conductivity values for brandies and vodkas

\begin{tabular}{|l|l|c|}
\hline \multirow{2}{*}{$\begin{array}{c}\text { Type of } \\
\text { drink }\end{array}$} & \multicolumn{2}{|c|}{ Conductivity limits, $\boldsymbol{\mu S} / \mathbf{c m}$} \\
\cline { 2 - 3 } & Genuine samples & Adulterated samples \\
\hline Brandies & From 22 to 196 & More than 196 \\
\hline Vodkas & From 2 to 58 & More than 58 \\
\hline
\end{tabular}

The interspecific difference in the values of specific conductivity is explained by the peculiarities of the production technology. In vodkas electrical conductivity mainly due to ionic composition used in the process water when using natural, untreated water with hardness up to 1 $\mathrm{mol} / \mathrm{m} 3$ specific conductivity will be higher than when using fixed and/or softened water with hardness up to $0.2 \mathrm{~mol} / \mathrm{m} 3$.

In brandies, the hardness of the water used to bring the drink to the specified volume fraction of ethanol also has a dominant influence on the value of specific electrical conductivity, however, unlike vodkas, cognacs and brandies also contain more than 700 chemicals that pass into the drink from wine materials or from oak during the aging process. Theoretically, it is even possible to create a stable linear relationship between the aging period of the drink and the specific electrical conductivity, provided that the technology is used in the same chemical composition of water and cognac spirits of the same raw material origin, differing only in the aging time in contact with oak wood. It is obvious that the coincidence of these conditions in practice is unlikely, which explains the lack of relationship between the aging period of cognac and brandy and the measured value of the specific electrical conductivity $\left(\mathrm{R}^{2}=0.15\right)$. The main explanation on these limits in the context of adulteration is that untreated (not purified) water with a higher content of solutes is very often used in producing adulterated spirits. That is why this method is only suitable to identify flagrantly falsified spiritous drinks. We also studied the stability during self-life of this identification criteria - after 6 month of storage the variation of conductivity values was no more than $10 \%$. Nevertheless, each plant, producing spiritous drinks deals with water of specific ionic contents, that is why it is possible to use conductivity as a criteria ti identify the producer of drinks in some cases.

Published By:

Blue Eyes Intelligence Engineering and Sciences Publication

(C) Copyright: All rights reserved.

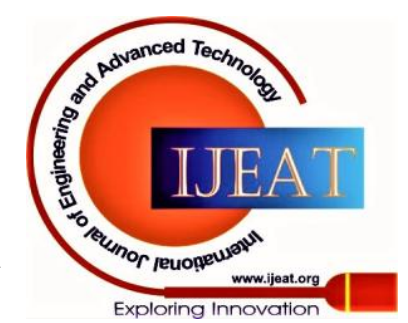


Typical UV-spectrum for brandies (Fig. 1) and vodkas (Fig 2) are shown below. Samples of brandies showed a spectral curve that has three characteristic extremes:

1. local maximum on the wavelength segment [270;290] $\mathrm{nm}$ (most often the maximum point is $280 \mathrm{~nm}$ );

2. local minimum at the wavelength interval [240; 260] nm;

3. the absolute maximum at the point $200 \mathrm{~nm}$.

The typical spectrum of vodkas is a decreasing function with an insignificant local minimum at $250 \mathrm{~nm}$.

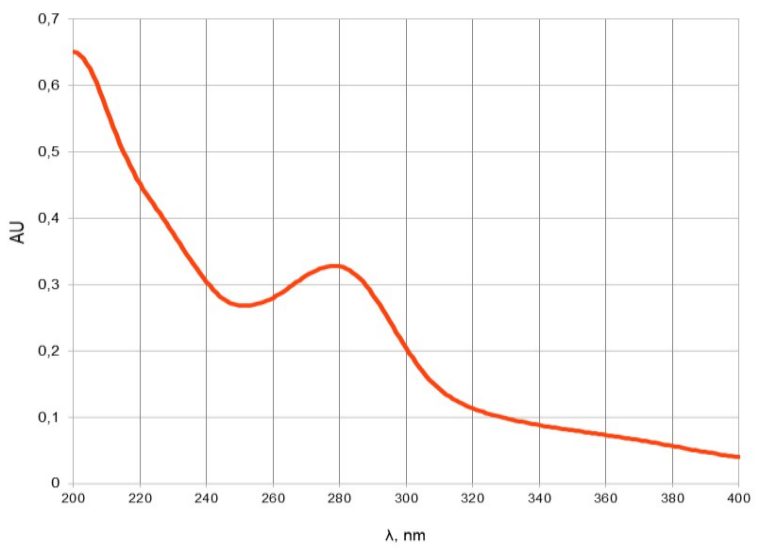

Fig. 1.Typical UV-spectra for brandies

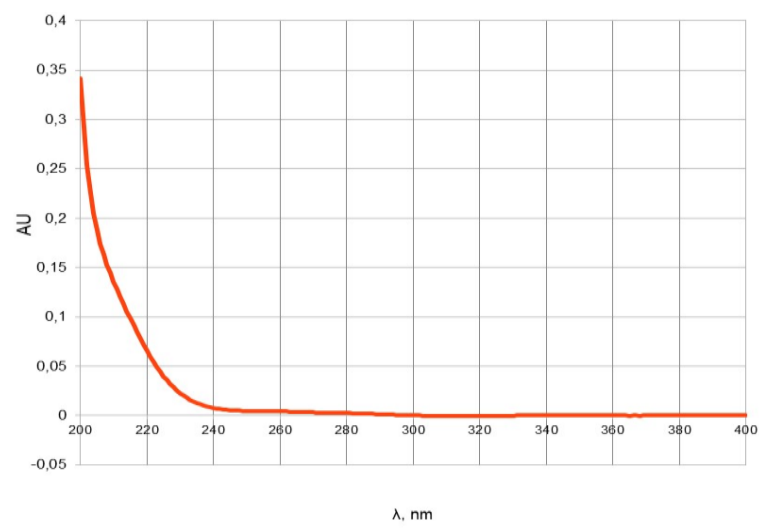

Fig. 2.Typical UV-spectra for vodkas

On the basis of pairwise intraspecific UV-spectra of all samples comparison with each other, the potential possibility of using the parameters of the UV-spectrum to identify batches of products is shown. UV absorption spectra that differ in the sum of squares of residuals (SSR) between the values of the absorption coefficient at wavelengths that make up the informative spectral band no more than the parallel registered spectra of the same sample were considered to coincide. The curves of the spectra were previously combined at the point of the right border of the segment of the informative spectral region. Such UV-spectra were considered unique if no coincidence with the spectra of another sample was obtained. In "non - unique" samples, the number of "erroneous" matches was estimated - the coincidence of the spectrum of this sample with the spectra of other samples. The reliability of identification was estimated as $100 \%$ minus the percentage of "erroneous" matches from the total number of samples studied. For brandies the spectra of 15 samples (12.10\%) are absolutely unique, the maximum number of non-identical matches was $13(10.48 \%$ of the total number of samples), the identification accuracy was at least $89.52 \%$. For vodkas, the spectra of 22 samples (46.80\%) are absolutely unique, the maximum number of non-identical matches was 3 ( $6.38 \%$ of the total number of samples), the identification accuracy was at least 93.6\%. Full experimental data in tabular form is presented in [14].

\section{B. A method on identifying and tracing spiritous beverages using UV-spectrometry and conductometry}

Fig. 3 shows a flowchart of the sample identification process in the alcohol certification system developed by author.

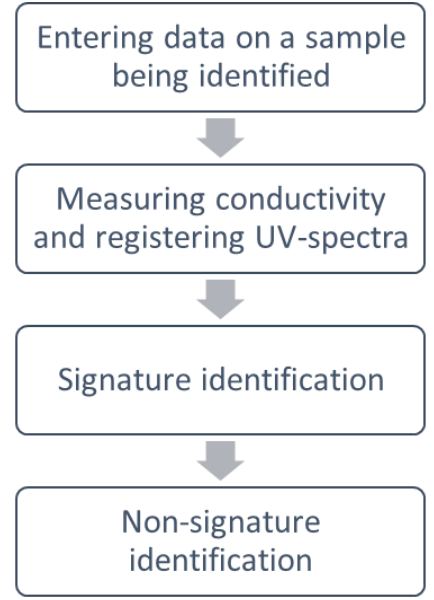

Fig. 3. Sample identification process [14]

Here is a step-by-step description of the algorithm. During the signature identification stage, the database is searched for signatures of reference samples with a characteristic value of specific electrical conductivity: for the identified sample and all reference samples, confidence intervals are formed for the specific electrical conductivity value, taking into account the deviation of $+/-10 \%$ from the measured value. Samples which confidence intervals intersect are considered to be similar in terms of specific electrical conductivity. The introduction of filtering the sample by the value of specific electrical conductivity is associated with the need to reduce the time of identification of samples. Next, the UV-spectrum of the identified sample is sequentially compared with the standards selected in accordance with the value of electrical conductivity (using the SSR criteria).

The stage of non-signature identification is carried out as follows. First, the measured value of the specific electrical conductivity is checked for compliance with the type of drink and for gross falsification according to the limits of variation established above. Next, the registered UV absorption spectra of the identified sample is typed according to typical spectrum of different types of products. During our research using k-means clusterization we found three typical spectrum clusters for brandies: French-style brandies (Fig. 4a), southern-style genuine brandies (Russia and CIS, Spain - Fig. 4b), adulterated brandies (Fig. 4c). UV-spectra of falsified vodka samples are characterized simultaneously by the following indicators

Published By:

Blue Eyes Intelligence Engineering and Sciences Publication

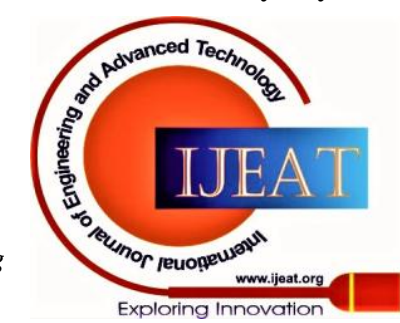


- the value of the absorption coefficient at a wavelength of $253 \mathrm{~nm}$ is $0.017 \mathrm{AU}$ and more;

- the ratio between the values of the absorption coefficients at the wavelengths of $253 \mathrm{~nm}$ and $270 \mathrm{~nm}$ is 1,250 or more.

Under these conditions, 2 samples were mistakenly classified as falsified, the accuracy of identification was $95.75 \%$.

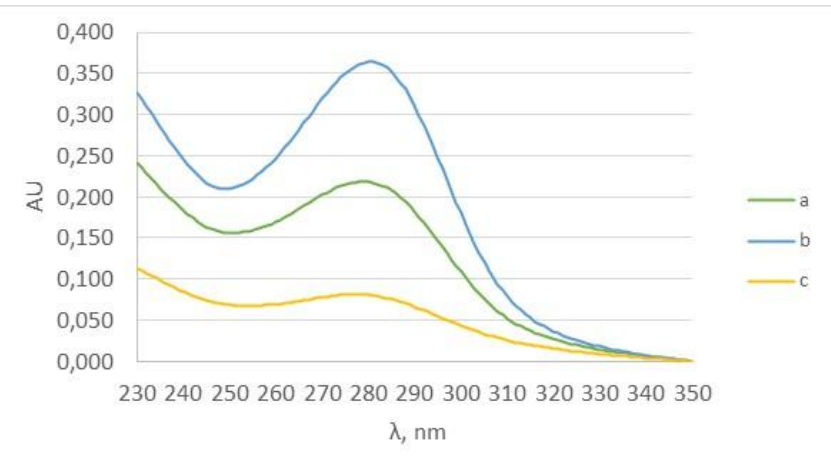

Fig. 4. Cluster spectra for barndy samples

As a result of the identification procedure, it is concluded that it is possible to identify the sample with the standard, as well as the presence or absence of signs of falsification according to non-signature criteria.

\section{CONCLUSION}

To sun it all up, Thus, we have proposed a comprehensive method for detecting adulterated alcoholic beverages, based on the combination of molecular spectroscopy in the UV region and conductometry, replacing expensive HPLC and GC methods. The proposed technology with 92\% identification accuracy is 6 times cheaper and 11 times faster than existing standard methods. Rough falsification is instantly cut off by the values of electrical conductivity characteristic of the water used in the technology of a particular enterprise. More sophisticated fakes are detected at the second stage by the characteristic shape of the absorption spectrum in the informative region at more than 200 wavelengths.

It is experimentally proved that for alcoholic beverages of various types: brandy and vodka - the shape of the UV-spectra curve and the limits of electrical conductivity differ significantly, which allows us to use these characteristics as distinctive features for identification purposes. Changes in the spectral and electrochemical characteristics of spiritous beverages during storage were studied. Reliable ranges of variation of spectral and electrochemical characteristics for authentic and falsified alcoholic products are determined. Based on the method of cluster analysis of UV absorption spectra, a mechanism for separating genuine, low-quality and falsified alcoholic beverages is proposed.

The methodology for the identification of spirits with a confidence level of at least $92 \%$ based on comparison of magnitude of conductivity and the parameters of the UV absorption spectra of the identified reference samples and the definition of similarity measure of samples.

To ensure the effective functioning of the information database, a method has been developed for approximating the curves of UV absorption spectra by a superposition of a third-degree polynomial and six Gauss curves with an $\mathrm{R}^{2}$ of at least 0.99999 .

A two-stage algorithm for the functioning of an information and analytical system for identifying alcoholic beverages using signature and non-signature identification methods has been developed.

Thus, a technical and organizational solution is proposed that provides identification of adulterated alcoholic beverages and counterfeit products on the basis of two-stage identification by analytical indicators.

At the same time, an important scientific task remains to justify similar criteria for other types of alcoholic products, including beer and beer drinks, wine and wine drinks, low-alcohol cocktails.

\section{REFERENCES}

1. Skurikhin, I. M. "Chemistry of cognac and brandy." DeLi Print", M (2005)

2. Park, Young Joon, Kyoung Rae Kim, and Jung Han Kim. "Gas chromatographic organic acid profiling analysis of brandies and whiskeys for pattern recognition analysis." Journal of agricultural and food chemistry 47.6 (1999): 2322-2326.

3. Ebeler, Susan E., Michael B. Terrien, and Christian E. Butzke. "Analysis of brandy aroma by solid-phase microextraction and liquid-liquid extraction." Journal of the Science of Food and Agriculture 80.5 (2000): 625-630.

4. Oseledtseva, I. V., T. I. Guguchkina, and E. M. Sobolev. "Dynamics of aromatic aldehydes and acids in cognac spirits and cognacs." Winemaking and viticulture 6 (2008): 15-17.

5. Panossian, A., et al. "Analysis of aromatic aldehydes in brandy and wine by high-performance capillary electrophoresis." Analytical chemistry 73.17 (2001): 4379-4383.

6. OIV. "Determination of the chromatic characteristics according to CIELab." Resolution Oeno 1/006 (2006).

7. Kazantseva, I. L., and V. M. Bulanov. "The Application of Spectral Luminescent Method to Examine Alcohol-Containing Liquids Produced Using Rectified Ethyl Alcohol." Theory and Practice of Forensic Science 14.4 (2019): 75-82.

8. Goldberg, David M., et al. "Phenolic constituents, furans, and total antioxidant status of distilled spirits." Journal of Agricultural and Food Chemistry 47.10 (1999): 3978-3985.

9. Gorjanovic, Stanislava Z., et al. "Polarographic assay based on hydrogen peroxide scavenging in determination of antioxidant activity of strong alcohol beverages." Journal of agricultural and food chemistry 58.14 (2010): 8400-8406.

10. Han, Jinsong, et al. "A hypothesis-free sensor array discriminates whiskies for brand, age, and taste." Chem 2.6 (2017): 817-824.

11. GOST 31732-2014 "Brandy. General specifications". URL : http://docs.cntd.ru/document/1200112849

12. GOST 12712-2013 "Vodkas and Special Vodkas. Specifications." URL : http://docs.cntd.ru/document/1200105674

13. Wojdyr, Marcin. "Fityk: a general-purpose peak fitting program." Journal of Applied Crystallography 43.5-1 (2010): 1126-1128.

14. Belkin Y. Razrabotka informacionno-analiticheskoj sistemy identifikacii spirtnyh napitkov na osnove kompleksa fiziko-himicheskih pokazatelej Dokt, Diss. [Development of an information and analytical system for identifying alcoholic beverages based on a set of physical and chemical indicators. Doct. Diss.].Moscow, 2013. 225 p.

\section{AUTHORS PROFILE}

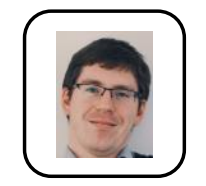

Yury Belkin, PhD, chair of Commodity Science and Expertise Department, Plekhanov Russian University of Economics. A specialist in digital commodity science concerning identifying adulterated foods.

Published By:

Blue Eyes Intelligence Engineering and Sciences Publication

(C) Copyright: All rights reserved.

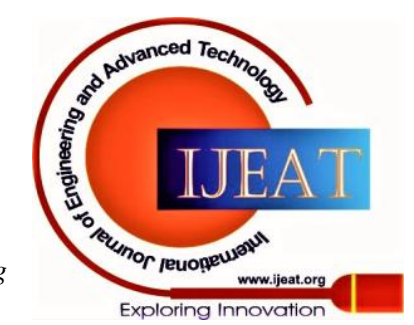

